\title{
LXVIII. Some experiments and observations on the substances produced in different chemical processes on fluor spar
}

\author{
Sir Humphry Davy LL.D. F.R.S. V.P.R.I.
}

To cite this article: Sir Humphry Davy LL.D. F.R.S. V.P.R.I. (1813) LXVIII. Some experiments and observations on the substances produced in different chemical processes on fluor spar , Philosophical Magazine Series 1, 42:188, 407-418, DOI: 10.1080/14786441308638358

To link to this article: http://dx.doi.org/10.1080/14786441308638358

电 Published online: 27 Jul 2009.

Submit your article to this journal $\pi$

Џll Article views: 2

Q View related articles $\sqsubset$ 
Again, 20 is composed of 4 and 5 : therefore divide the circle into 4 parts, and then by the side of 20 subdivide each division into 5 .

For the prime numbers take one side from the line of polygons, and with it mark 3 divisions as exactly as possible. Take these 3 divisions between the extremes, and divide the circle into as many divisions of 3 sides each, as are necessary; then with one side between the extremes trisect the divisions.

N.B. On the line of sines, the sine of 53 degrees is equal to the chord of three sides of a polygon of 23 sides nearly.

For the purpose of very readily measuring degrees, bisecting angles and lines, the sectograph (if required) may be made to consist of three points only in the line, besides the central point.

LXVIII. Some Experiments and Observations on the Sutstances produced in different chemical Processes on Flusor Spar. By Sir Hu MPhay Davy, LL.D. F.R.S. V.P. R.I.*

I

$I_{N}$ the Bakerian Lecture for 1808 I have given an account of an experiment on the combustion of potassium in silicated fluoric acid gas, in which the gas was absorbed, and a fawn-coloured substance formed, which effervesced with water, and left after its action on that fluid, a residuum which burnt when heated in oxygen, reproducing silicated fluoric acid gas; and I concluded from the phrnomena, that the acid gas was decomposed in the process, that oxygen was probably separated from it by the potassium, and that the combustible substance was a compound of the siliceous and fluoric bases.

The experiment of burning potassium in silicated fuoric acid gas was made likewise by MM. Gay-Lussac and Thenard, before I published any account of my researches on this phanomenon. It was indeed one of the most obvious applications of polassium, and it occurred to many others, as well as to myself, that it might be made, immediately after I discovered that metal,

MM. Gay-Lussac and Thenard drew the same conclusions as I did, namely, that the acid gas was probably decomposed during the action of potassium on silicated fluoric acid; but their general views differed from mine in this re-

- From the Philosophical Transactions for 1813, part ii. 
spect, as they supposed that no part of the inflammable matter was derived from silica, and they likewise reasoned on the phrenomena with more caution.

At the time that my conclusions were drawn, I was ignorant of the true nature of the muriatic acid. After 1 had tried in vain to decnmpose oxymuriatic gas, and after I had found that the compounds of this substance with phosphorus, sulphur, and the metals combined with ammonia without any decomposition, and produced compounds in which no oxygen could be discovered; I was forcibly struck by the analogy between the oxymuriatic and the fuoric compounds, and led to doubt of the justness of my ideas respecting the nature of fluoric acid.

I tried an experiment on the comparative quantities of fluate of lime, formed from equal volumes of silicated fluoric acid gas, one of which had been acted upon by potassium, and then exposed to solution of ammonia, the other had been absorbed by solution of ammonia: and $I$ found the proportion of calcareous fluate nearly one-third Jargei in the latter case. This result at first seemed favourable to my early ideas, that the acid contained a peculiar infammable basis, which was separated by the potassium, and existed in the combustible substance insoluble in water: but it could not be considered as decisive on the question; for it occurred to me as possihle, that this substance might be silicum, or the basis of silica united to a much smaller proportion of the fluoric principle than that existing in silicated fluoric acid.

During the period that I was engaged in these investiga tions, I received two letters from M. Ampere, of Paris, containing many ingenious and originai arguments in favour of the analogy between the muriatic and fluoric compounds. M. Ampere conmunicated his views to me in the most liberal manner; they were formed in consequence of my ideas on chlorine, and supported by reasonings drawn from the experiments of MM. Gay-Lussac and Thenard.

Before $I$ enter upon the detail of the investigations which promise to elucidate the nature of the fluoric componnds, it will be right to describe those substances produced from fluor spar, which have been the principal objects of my experiments, and to mention the different hypothetical views that may be formed respecting them.

The first of these substances is the silicated fluoric acid gas, whicb was discovered by Scheele, and examined in its pure state by Priestley. It is formed by heating a mixture of fluor spar, powdered glass, and sulphuric acid. It is a very 
very heavy elestic fluid, its specific gravity being nearly forty-eight times as great as that of hydrogen. It produces, according to my brother Mr. John Davy, a quantity of silica equal to $\frac{152}{1000}$ of its own weight by its action upon water, and a quantity equal to $\frac{614}{1000}$ of its weight by its action upon solution of ammonia. It condenses twice its own volume of ammonia, and forms a solid salt, volatile when free from water without decomposition.

Liquid fluoric acid, the second of these substances, was discovered by Scheele, but first obtained in its pure form by MM. Gay-Lussac and Thenard. It is procured by heating concentrated sulphuric acid and pure fluor spar, in retorts of silver or lead, and receiving the product in receivers of the same metals artificially cooled. It is a very active substance, and must be examined with great caution. According to my experiments, its specific gravity is 1.0609*. It produces a high degree of heat when mixed with water; and such is its degree of attraction for water, that it becomes denser by combining with that fluid. By adding water, in very snall quantities at a time, to pure liquid fluric acid, I found that its specific gravity gradually increased till it became 1.25: it is, I believe, the only known body possessed of this property.

The third substance is fluo-boric acid gas, which was discovered by MM. Gay-Lussac and Thenard. It is produced by intensely heating, in an iron tube, a mixture of dry boracic acid and fltor spar, or by gently beating in a glass retort a similar mixture with sulphuric acid. Its spe. cific gravity is rather more than thirty-two times as great as that of hydrogen. It forms a solid salt, volatile wittout decomposition, by condensing its own volume of ammonia. The ammoniacal salt dissolved in water and distilled, affords boracic acid.

The most important phænomena of chemical change, in which these bodies operate, that may be supposed to illustrate their nature, is their agency upon potassium and other metals. The action of potassium upon silicated fluoric gas has been already referred to. MM. Gay-Lussac and Thenard, by heating potassium and sodium in fluo-boric acid gas, obtained fluate of potassa or soda, and the basis of the boracic acid; and by exposing potassium to liquid Guoric acid, their results were hydrogen and acid fluate of potassa.

* Unless it is distilled through tubes and into vessels of pure silver, its specifie gravity is greater; it readily dissolves tin, and slowly dissolves lead, and after being long kept in vessels of pure silver, it is found to have taken ip a small portion even of that metal. 
Three hypotheses may, according to sound analogies, be formed on the nature of the fluoric combinations. In the first, which is that generally adopted, the silicated fluoric acid gas is supposed to be a compound of silica and a peculiar acid, itself consisting of inflammable matter and oxygen; fluo-boric acid gas, a compound of boracic acid and the same acid; and pure liquid fluoric acid as water combined with the acid.

In the second hypothesis, that which I have alluded to in the beginning of this paper, and that adopted by M. Ampere, the silicated fluoric acid is conceived to consist of a peculiar undecompounded principle, analogous to chlorine and oxygen, united to the basis of silica, or silicum; the fluo-boric acid of the same principle united to boron; and the pure liquid fluoric acid as this principle united to hydrogen.

in the third hypothesis, which probably would have been formed by the disciples of the phlogistic school of chemistry, had they been acquaiuted with the facts, the liquid fluoric acid is considered as an undecompounded body; and the metals and inflammable bodies as compounds of certain unknown bases with hydrogen : silicated fluoric acid gas, on this idea, must be regarded as a compound of the fluoric acid with the basis of silicum, and fluo-boric acid gas as a compound of fluoric acid and the basis of boron.

Whoever will consider, with attention, the different facts that have been brought forward by Scheele, Gay-Lussae and Thenard, John Davy, and myself, will find that they will almit of explanation on either of these hypotheses; and as, in all the cases yet brought forward, of the most simple chemical action of other bodies on the fluoric substances, more than one new form of matter is produced, no explanation of the phænomena can at present be given withnut involving suppositions.

It is not easy to devise simple experiments to ascertain which of these hypotheses is true; yet, in admitting strict analogical reasoning, it is easy to show which is most conformable to the general series of chemical facts.

Those acids which are known by direct experiments of decomposition by heat, to consist of oxygen, bases, and water, such as the strongest sulphuric and nitric acids and hydro-phosphorous acid, when they are acted on by ammonia, afford moisture: this is easily proved, by causing them to absorb ammoniacal gas in glass retorts, and genlly heating the mixture; when water immediately appears. On this view, it occurred to me, if the liquid fluoric acid was 
a compound of water, and inflammable bases, and oxygen, that water ought to be produced when it was made to combine with ammonia. It was not possible to make the experiment in glass vessels, as the acid acts with great violence on glass, producing silicated fluoric acid gas. I had recourse, therefore, to an apparatus made of platina. A small tray of platina was filled with pure liquid fluoric acid, and introduced into a tube of platina connected by proper stop-cocks with a mercurial gazometer, filled with ammonia; the end of the platina tube was closed by a brass stopper, and a communication made between the ammonia and the fuoric acid; the ammonia was gradually absorbed, producing heat; and white fumes sometimes rose into the gas-holder, so that it was necessary from time to time to cut off the commonication; ammoniacal gas was supplied till no more absorption took place. When the tube was quite cool, the stopper was removed, and the result examined; the interior contained a white crystaline mass, but there was no appearance of fluid*. A polished brass tube, cooled by means of ice, was held over the aperture of the platina tube, and it was gently heated till the sait began to sublime, but no moisture was found condensed in the cold tube of brass.

This experiment is unfavourable to the idea, that the liquid fluoric acid contains water; and the following result is likewise unfavourable to the idea that it consists of an inflammable basis united to oxygen. Solid and perfectly dry fluate of ammonia was introduced into a tray of platima, with about an equal quantity of potassium, and the tray was heated in a small tube of glass connected with a mercurial apparatus. A violent action took place, gas was disengaged with great violence, which remained for some time clouded; the application of heat was continued till the tube was red: it was then suffered to cool, and the results examined. Much white matter, which proved to be fluate of potassa, had been carried by the violence of the action out of the tray of platina into the glass tube; and a little potassium had sublimed in the tube. The tray contained a considerable portion of potassium, and a saline matter, which had all the characters of fluate of potassa. The gas disengaged, consisted of ammonia and hydrogen, to each

* It is necessary that pure liquid fluoric acid, i. e. that which has the lowest specific gravity, be used for this experiment. The first time that $I$ made it, I obtained moisture, owing to my having formed the hydro-fluoric acid by means of sulphuric acid that had not been previously boiled, and which must have coutained more than one proportion of water. 
other in volume nearly as two to one; but the experiment cannot be considered as decisive on this point, as no particular precautions had been taken to dry the mercury.

Now, if there had existed oxygen combined with an inflammable basis in the fluate of ammonia, it might have been expected to have been separated, or at least to have formed a new combination during the action of potassium upon the fluate of ammonia, which is the case with such ammoniacal salts as contain acids in which oxygen is an element. Thus nitrate of ammonia acted on by potassium, as I have found, affords azote and ammonia; and sulphur is partly disengaged, and partly newly combined during the agency of potassium in excess upon sulphate of ammonia.

The action of potassium upon fluate of ammonia is precisely similar to its action upon muriate of ammonia, in which, as I have found by numerous experiments, ammonia and hydrogen to each other in volume as two to one are disengaged, and muriate of potassa (potassane) formed.

All the hydrates, that is, all the substances which contain definite proportions of water, united to acids, alkalies, or oxides, which are fluid, or capable of being rendered fuid by heat, when exposed to the chemical agency of Voltaic electricity, undergo decomposition, and their inflammable principles, either pure, or combined with a smaller proportion of oxygen, are disengaged at the negative surface in the circuit, and their oxygen at the positive surface. Thus sulphuric acid affords sulphur and hydrogen at the negative surface, and the hydro-phosphorous acid, phosphuretted hydrogen and phosphorus, and nitric acid nitrous gas; and all these bodies yield oxygen at the positive surface.

I undertook the experiment of electrizing pure liquid fluoric acid, with considerable interest, as it seemed to offer the most probable method of ascertaining its real nature; but considerable diffeculties occurred in executing the pro: cess. The liquid fluoric acid immedately destroys glass, and all animal and vegetable substances; it acts on all bodies containing metallic oxides; and I know of no sub. stances which are not rapidly dissolved or decomposed by it, except metals, charcoal, phosphorus, sulphur, and certain combinations of chlorine.

I attempted to make tubes of sulphur, of muriates of lead and of copper containing metallic wires, by which it might be electrized, but without success. I sticceeded, however, in boring a piece of horn silver in such a manner, that $I$ was able to cement a platina wire into it, by means of a 
spirit lamp; and by inverting this in a tray of platina flled with liquid fluoric acid, I contrived to submit the fluid to the agency of electricity in such a manner, that in successive experiments it was possible to collect any elastic fluid that might be produced. Operating in this way, with a very weak Voltaic power, and keeping the apparatus cool by a freezing mixture, I'ascertained that the platina wire at the positive pole rapidly corroded, and became covered with a chocolate powder; gaseous matter separated at the negative pole, which I could never obtain in sufficient quantities to analyse with accuracy; but it inflamed like hydrngen. No other inflammable matter was produced when the acid was pure.

In a case in which the acid had been condensed in a tube of lead, joined by a solder containing tin, a large quantity of powder separated at the negative surface of a dark colour, and which appeared to be tin mixed with a subfluate; the powder burnt when heated in the air, and gave fluoric fumes when treated by potassa and sulphuric acid.

I attempted to electrize the liquid fluoric acid, by making plumbago the positive surface; but the plumbago was quickly destroyed, a subfluate of iron was deposited on the negative surface, and the liquid became turbid and black. When a point of charcoal attached to a wire of platina was made positive, the effects were similar to those produced by a platina wire alone; for the acid speedily penetrated through the pores of charcoal, and the platina, in consequence, became a point of contact with the fluid.

I applied the power of the great Voltaic batteries of the Royal Institution to the liquid fluoric acid, so as to take sparks in it. In this case, gas appeared to be produced from both the negative and the positive surfaces; but it was probably only the undecompounded acid rendered gaseous, which was evolved at the positive surface, for during the operation the fluid became very hot, and speedily diminished. The manner in which the surrounding atmosphere became filled with the fumes of the fluoric acid, rendered it, indeed, very difficult to examine the results of any of these experiments; the dangerous action of these fumes has been described by MM. Gay-Lussac and Thenard, and I suffered considerable inconvenience from their effects during this investigation. By mere exposure to them in their uncondensed state, my fingers became sore beneath the nails, and they produced a most painful sensation, which lasted for some hours, when they came in contact with the eyes. 


\section{4}

Experiments on the Sulstances produced

The phænomena of the Voltaic electrization of fluoric acid present no evidences in favour of its containing a peculiar combustible substance and oxygen; and the most simple mode of explaining them is by wupposing the fluoric acid, like muriatic acid, composed of hydrogen, and a substance, as yet unknown, in a separate form, possessed, like oxygen and chlorine, of the negative electrical energy, and hence determined to the positive surface, and strongly attracted by metallic substances.

This view is much more conformable to the general order of chemical and electrical facts than the third hypothesis, just now mentioned.

It is indeed possible to conceive, if the metals be regarded as compounds of bydrogen, that the hydrogen may be produced from the metal, positively electrified at the time that the acid combines with its supposed basis, and that this hydrogen may be transferred to the negative surface: but this supposition involves a multitude of others; and the results of the electrization of fluoric acid are analogous to most of the results of the electrization of water and muriatic acid, both of which are shown by analysis and synthesis to be compounds of hydrogen; and in the electrical decomposition of these bodies, their characteristic element is generally combined with the positive metallic surface.

In the Bakerian Lecture for 1810 I have given an account of the action of potassium upon pure silica. In this process, the potassium acquires oxygen; and a combustible substance, which cunsists either of the basis of silica, or the basis of silica combined with potassium, appears. In supposing the silicated fluoric acid gas to be composed of this basis and the fluoric principle, it is easy to explain the action of potassium upon it, and the complicated phrenomena, occasioned by the agency of water, and acids, and oxygen, on the results of this action. The potassium must be conceived to attract a part of the fluoric principle from the siliceous basis, or to form a triple compound, from which silicated fluoric acid gas is capable of being reproduced, in consequence of the comhination of a part of the potassium and siliceous basis with oxygen; and on this idea the cause of the apparent loss of the fluoric principle, in the experiments on the action of ammonia on the product of the combustion of potassium in silicated fluorie acid gas, becomes obvious.

Assuming then from the analogy with chlorine, that the different fluoric compounds consist of inflammable bodies united to a peculiar principle, it follows that all attempts to decompose 
decompose the fluoric acids, by combustible substances, can lead to no other result, than that of occasioning new combinations of the fluoric principle; and the only methods which seemed plausible for obtaining this principle pure, after that by electrical decomposition had failed, were by the action of oxygen or chlorine on certain of its compounds. Chlorine is, in certain instances, detached from hydrogen by oxygen; and oxygen, in a number of cases, is detached from metals by chlorine : I thought it therefore probable, that the fluoric principle might, in some process, be separated from bases by either chlorine or oxygen.

In selecting compounds for experiments of this kind, I was guided by the relative attractions of the fluoric and muriatic acids, of chlorine and oxygen. Horn silver and calomel, and muriate of potassa are not decomposed by fluoric acid; but fluate of silver, of mercury, and of potassa are easily decomposed by muriatic acid: I therefore conceived, that the fuoric principle would most likely be expelled from the dry fluates of silver, mercury, and potassa by chlorine.

I made some pure ftuates of silver and mercury, by dissolving the oxides of these metals in fluorie acid, and $\mathbf{I}$ heated them in small trays of platina; much fluotic acid was driven off in this process, which I continued in the case of the fluate of mercury till the salt began to sublime, and in that of the fluate of silver till it was red hot.

The dry salts were introduced in small quantities into glass retorts, which were exhausted and then filled with pure chlorine: the part of the retort in contact with the salt. was heated gradually till it became red. There was soon a strong action, the fluate of mercury was rapidly converted into corrosive sublimate, and the fluate of silver more slowly became horn silver. In both experiments there was a viclent action upon the whole of the interior of the retort. On examining the results, it was found that in both instances there had been a considerable absorption of chlorine, and a production of silieated fluoric acid gas, and oxygen gas.

I tried similar experiments, with similar results, upon dry fluates of potassa and soda. By the action of a red heat, they were slowly converted into muriates with the absorption of chlorine, and the production of oxygen, and silicated fluoric acid gas, the retort being corroded even to its neck.

The obvious explanation of these phrnomena is, that a particular principle, the acidifying matter of the fluoric acid, combined with the metals, is expelled from them by 
the stronger attraction of the chlorine, and that this prin ciple coming in contact with glass decomposes it by its attraction for the silicum and sodium; and separates them trom the oxygen with which they were combined.

I made various attempts to procure the fluoric principle in a pure form. I heated the fluates of potassa and soda in trays of platina, in a tube of platina comected with a vessel filled with chlorine. In this case the fluates were converted into muriares, with a considerable increase of the weight of the tray; and the platina was violently acted upon, and covered with a reddish-brown powder; and in the instance in which fluate of potassa was used, a compound of fluate of platina and muriate of potassa was formed.

There was a considerable absorption of chlorine; but no, new gaseous matter could be discovered in the gas in the tube.

I tried to obtain the fluoric principle pure, by decomposing the fluates in a tube of silver, but with no better success; the silver was acted upon both by the chlorine and the Auoric principle, and rapidly dissolved. I used glass tubes coated with resin of copper (cuprane) and hornsilver (argentane), on which I concluded that the fluoric principle would have no action from the decomposition of fluate of silver by chlorine; but at the degree of heat required to decompose the fluoric salts, the muriates were always fused, the glass violently acted upon, and silicated flworic acid gas formed.

In one instance, in which fluate of potassa had been heated in a platina tray and tube, in which muriate of potassa had been fused, for the purpose of defenting the interior, as much as possible, from the action of the fluoric principle, the gas, when disengaged into the atmosphere, had a peculiar smell, different from that of chlorine, (which certainly formed the greatest proportion of the elastic matter,) and more disagreeable ; and dense white fumes were produced by its action upon the air. A portion of this gas thrown into a glass receiver, over mercury, acted upon the glass, and silicated fluoric acid gas was generated. On examining the platina tray, bowever, it was found corroded, and the reddish.brown powder formed.

In the course of these investigutions, I made several attempts to detach hydrogen from the liquid fluoric acid, by the agency of oxygen and chlorine. It was not decomposed when passed through a platina tube heated red with chlorine, nor by being distilled from salts containing abun. 
dance of oxygen, or thase containing abundance of chlorine.

I distilled the fluates of lead and mercury with phosphorus and sulphur, with the hope of obtaining compounds of the fluoric principle with phosphorus and sulphur. In all experiments of this kind, a decomposition took place, and the glass tubes employed were violently acted upon, and sulphurets and phosphurets were formed. When I used tubes lined with sulphur the decomposition was less perfect; but minute quantities of limpid fluid condensed in a part of the tube cooled by ice, both in the cases whein sulphur and when phosphorus were used; it had the appearance of hydro-fuoric acid, and speedily dissipated itself in white fumes. Whether they were that substance which had obtained its hydrogen from these inflammable bodies, or compounds of sulphur and phosphorus with the fluoric principle, I have not ascertained; but the first opinion seems most probable.

When I heated fluate of lead and finely powdered charcoal strongly in the air, the lead became revived, and white fumes were produced. I thought it probable, that in this case a compound of fluorine and charcoal was formed; but on trying the experiment in a close vessel of platina, no change took place; and it evidently depended upon the presence of hydrogen in the vapour of the atmosphere, or in the flame of the spirit lamp, by which the experiment was marle, and I found muriate of silver decomposed, and silver produced under the same circumstances.

From the general teuor of the results that $I$ have stated, it appears reasonable to conclude that there exists in the fluoric compounds a peculiar substance, possessed of strong attractions for metallic bodies and hydrogen, and which combined with certain inflammable bodies forms peculiar acids, and which, in consequence of its strong affinities and high decomposing agrencies, it will be very difficult to examine in a pure form; and for the sake of avoiding circumlocution, it may be denominated fluorine, a name suggested to me by M. Ampere.

From experiments that $I$ have made on the composition of the fluoric combinations; and which I shall soon have the honour of communicating to the Society, it appears that the number representing the definite proportion in which fluorine combines, is less than half the number representing that in which chlorine combines; and hydrates in becoming flates lose weight; so that on the generally received idea of the existence of a peculiar acid in the Vol, 42. No. 188. Dec. 1813. D d fluates, 
Aluates, and of their being compounds of oxides, with an acid containing oxygen, that acid, according to the law of definite proportions, must contain more oxygen in proportion to its quantity of inflammable matter than water; which is highty improbable, and contrary to all analogies.

Dr. Wullasion bas found, that the fuoric combinations have very low pewers of refracting light, and particularly the pure fluoric acid; so that the refracting powers of fluorine will probably be found lower than those of any other substance, and it appears (") possess higher acidifying and saturating powers than either oxygen or chlorine.

It is easy to perceive, in following the above theory, that all the ideas current in chemical authors respecting the fluoric combinations, must be changed. Fluor spar, and other analogous substances, for instance, must be regarded as binary compounds of metals and fluorine.

Many objects of inquiry arise, likewise, from these new views: the topaz contains the fluoric principle; but new experiments are required to show whether that gem is a true silicated fluate of alumina, or a compound of the inflammable bases of alumina and silica with fluorine.

I have ascertained that the chryolite yields no silicated fluoric gas, when acted on by sulphuric acid; but merely pure fluoric acid: but $I$ have not continued the research so far, as to determine whether it contains fluorine united to inflammable matter only, or fluorine and oxygen.

LXIX. A new Theory of Light; with Experiments to prove that Blackness arises from the Reflection of Indigo and Red-orange on the seven prismatic Rays of Light. By Joesph Reader, M.D.

\section{To Mr. Tilloch.}

SIr, $-O_{N}$ looking over my library, I find that Sir Isaac Newton took his ideas of blackness or darkness from $D e s$ Cartes, who observed * "that black suffocates or extinguishes the rays that fall upon it; whereas white reflects them." Mr. Boyle taking up this opinion says, "Many learned men supposed that suow affects the eyes not by a borrowed light, but by a native one; but having placed a quantity of snow in a room, from which all foreign light was carefully excluded, neither be nor any other person could perceive it." To try whether white bodies reflect more light than others, he held a sheet of white paper in a

* Dioptricks, p. 50. 